ORCID: 0000-0002-9056-1180

Maynooth University, Ireland

Leah.OToole@mu.ie

\title{
Participant Action Research (PAR) for early childhood and primary education: the example of the THRIECE project
}

\begin{abstract}
Summary
This paper explores the potential benefits of Participant Action Research (PAR) for early childhood and primary education. It presents the example of the Erasmus + funded THRIECE (Teaching for Holistic, Relational and Inclusive Early Childhood Education) project, and drawing on the reflections of its participants, supports PAR as a respectful, inclusive, relevant approach to educational research that can lead to deep personal and intercultural learning. It highlights the importance of embracing the 'messiness' of action research, and allowing its non-linear complexity to enhance both process and outcomes. It explores the potential of PAR to allow for investigation of and value for the embodied, tacit knowledge and understandings of expert educators, supporting continuous development of practice and providing the language for educators to explain their approaches. Finally, it identifies the crucial nature of a relational approach for the success of Participant Action Research.
\end{abstract}

Keywords: Participant Action Research, holistic, inclusive, relational education

Słowa kluczowe: uczestniczące badania interwencyjne, edukacja holistyczna, włączająca, relacyjna

\section{Participant Action Research}

Historically, educational research was guided by a positivist paradigm. This was a world view that reified 'scientific' research methods - experiments, observations, measuring behaviours, etc. - to find an objective constant truth and universal 'laws' that can be generalised to all (Mukherji, Albon 2018). However, researchers now tend to acknowledge the limitations of positivism when investigating human beings in context. For example, the work of influential socio-cultural theorists like Barbara Rogoff (2003) highlighted the extensive impact of culture on learning and development, rendering the view of a universal child who developed in linear and predictable ways largely extinct. Bioecological theory (Bronfenbrenner, Morris 2006) also argued that it is futile to try to 'control' for interaction between variables like social class or ethnicity as required by positivism, since "no process occurs outside of a context. And if we want to understand context, we need to take it into account, not pretend to control it away" (Steinberg et al. 1995: 424). Equally, some of the most important influencers of children's learning and development, like the quality of 
relationships and interactions, are very difficult, if not impossible to measure numerically or scientifically (O'Toole et al. 2019).

Therefore, in recent years, educational research has drawn on more nuanced paradigms such as interpretivism/constructivism, which rejects the notion of one objective truth generalisable to all people and contexts (Mukherji, Albon 2018). Rather, research in this vein sees knowledge as socially constructed and situated within human values and contexts. It seeks to understand the complexities of human experience from multiple perspectives, and is an interactive research process between the researcher and the researched. Within this paradigm, no attempt is made to find a single answer to a problem, but rather behaviour is seen as context-dependent, relying on factors such as perspective, language, place in history, and the values of the researcher and the researched (Blair 2010).

This perspective can be further expanded into a critical paradigm, recognising the impact of politics and power dynamics that shape the context of people's lives. Critical approaches to research are similar to interpretive approaches in that they reject all claims of objective 'truth', but the difference lies in how 'truth' is seen to be constructed. The critical paradigm views reality as constructed on the basis of power, and 'truth' as a system of socio-political power (Lather 2006). It argues that traditionally the 'experts know best' mentality has been used by schools and organisations to discount the perspectives of those being researched, children and their families (Giangreco, Taylor 2003), and by academic researchers to discount the expertise of practising educators (Sullivan et al. 2016). However, critical research focuses on the subjective experiences, perspectives and views of those who have traditionally been the 'subjects' of research within a socio-political context (Giangreco, Taylor 2003). Important to a critical perspective is the idea that the researcher him or herself is a key part of the human equation making up the research situation (Mukherji, Albon 2018). All research is rooted in the perspective of the researcher in socio-political, gendered, cultural and linguistic terms, and perhaps this is inevitable. As Kenneth Gergen puts it, "Perhaps our best option is to maintain as much sensitivity as possible to our biases and to communicate them as openly as possible. Value commitments may be unavoidable, but we can avoid masquerading them as objective reflections of truth" (Gergen 1973: 312).

Such paradigmatic shifts have allowed for the development of new and exciting methodologies for educational research that move beyond positivist ideas of scientific measurement of outcomes. In particular, recent years have seen increasing recognition of the power of Action Research whereby educators interrogate their own practice in systematic and deeply engaged ways, with a view to elucidating values and improving educational practice (Sullivan et al. 2016). In traditional research, researchers stand outside a situation and objectively investigate it scientifically; very often in educational research this involved academics from outside the educational setting studying educators and children, or introducing and measuring the impact of specific interventions developed by the academics themselves, often without any input from those being studied. Action researchers, on the other hand, are 'insiders' who seek to evaluate and improve their own work (Baumfield 
et al. 2013). Outside academics can contribute and support such research, but educators must be core to educational action research (McDonagh et al. 2019).

Participant Action Research (PAR) is a specific form of action research involving "the active participation of researchers and participants in the co-construction of knowledge; the promotion of self and critical awareness that leads to individual, collective, and/or social change; and the building of alliances between researchers and participants in the planning, implementation and dissemination of the research process" (McIntyre 2008: ix). PAR has gained prominence in recent years due to increasing recognition of the need to engage respectfully with research participants' lived experiences, rather than imposing the views of external researchers. PAR is particularly relevant to projects that involve emotional complexity (Klocker 2015) and that are interested in social justice (Zhu 2019) for children or young people (Shamrova, Cummings 2017). PAR views the adults and children in educational settings as co-researchers, with agency and capacity to contribute, rather than 'subjects' upon whom research is conducted.

\section{An example of Participant Action Research: the THRIECE project}

THRIECE (Teaching for Holistic, Relational and Inclusive Early Childhood Education) was an Erasmus + funded project with ten partners across three European countries: Poland, Portugal and Ireland, and additional associate partners in the UK, USA and Ireland. Its aim was to explore, define and illustrate the highly contested concept of 'quality' in early childhood and primary education. In many countries, system-level definitions of quality focus on structural quality (rules for accreditation of settings, staff requirements, health and safety, etc.) and outcome measures of children's development, often with a focus on 'school readiness' (O'Toole et al. 2019). Structural quality is easily measured through quantitative indicators, and many standardised tools exist to measure developmental outcomes. Traditional positivist understandings of quality education are therefore more likely to focus on these elements (O'Toole et al. 2019). However, THRIECE highlighted the often-neglected area of process quality: interactions and relationships within settings, including the role of play, and relationships with families, between staff and children, and among children. As the highly influential CoRe (Competence requirements in early childhood education and care) research argues from a systemic perspective "the acknowledgement of the importance of the actors (practitioners, children, families etc.) and their interactions to establish quality on a day-to-day basis requires emphasis on its relational and processual aspects" (Urban et al. 2012: 509-510).

The definition of 'quality' developed by the THRIECE project opposed the neoliberal focus on standardisation, quantitative measurement and narrowing of curriculum (Sahlberg 2014) and instead identified three elements of process-informed quality: that early childhood and primary education should be holistic, relational and inclusive. The focus of the current paper is the development of the THRIECE research as an example of PAR, and how the project team worked together to define these concepts and identify what they 
looked like in practice. For further explication of the concepts themselves, see O'Toole et al. (2019). The outcomes of the project were three interconnected online modules for early childhood and primary educators ${ }^{1}$ focused on holistic, relational and inclusive education, as well as three international conferences on these themes, one held in each of the partner countries.

\section{Putting together the THRIECE team}

A core value of THRIECE was the centrality of relationships for learning and development, and this was the lived reality of its work from the beginning. The specific partners for this project were selected due to pre-existing successful working relationships, and the partnerships between the universities were developed to begin with. Marino Institute of Education (MIE), the coordinating partner, is an Associated College of Trinity College Dublin (TCD), and in recent years their association has been strengthened through a joint trusteeship relationship. MIE and TCD enjoy an established and growing relationship of collegiality, particularly with regards to research. The partners from MIE met those from University of Gdansk (UG) at the ATEE (Association for Teacher Education in Europe) conference in Riga in 2013, and met the partners from the University of Porto in 2016 at the ECER (European Educational Research Association) conference in Dublin. Existing collegial and warm personal relationships were leveraged to begin the creation of the THRIECE team.

Once the universities were in place, we employed a method often used in educational research known as 'snow-balling' (Mukherji, Albon 2018), whereby existing participants recruit further participants. Each university identified an early years setting and a primary school in their country with whom they had existing relationships, and who had a dynamic staff team that possessed the skills and interest to take part in a project on holistic, relational and inclusive education. These specific educational settings were invited to take part based on their existing good practice - with concepts so potentially nebulous, it was important to have examples of holistic, relational, inclusive practice with which to animate our work. The Polish partners were Centrum Zabawy i Edukacji Zyrafa in Gdansk and Zespół Szkolno-Przedszkolny nr 3 in Gdynia. The Irish partners were Carlow Educate Together National School in Carlow and An Cosán in Tallaght, Dublin. Play Together Preschool which is co-located with Carlow ETNS was an initial partner also but unfortunately was ineligible for funding. Such was the commitment of the Play Together partners to THRIECE that they maintained their engagement with the project as unfunded associate partners. The Portuguese partners were Agrupamento de Escolas Alexandre Herculano and Agrupamento de Escolas Soares dos Reis. Additional associate partners also added their expertise to the team - the Irish Cognitive Analytic Therapy Association (ICATA), the Association of Cognitive Analytic Therapy (ACAT) in the UK, the University of New

1 These modules are available free of charge at www.thriece.eu, 1.07.2020. 
York at Buffalo, and Teachers' College, Columbia University in New York. One of the key roles of the associate partners was to audit and ensure high quality of the online modules, but they also provided ongoing feedback and support for the work of the core project team.

Once the team was in place, and Erasmus+ funding was secured, the work of the project began in earnest, and when the Project Coordinator transferred employment to the Froebel Department of Primary and Early Childhood Education in Maynooth University, Ireland, MU became an additional associate partner.

\section{PAR in action}

The work of THRIECE centred on deconstructing the concepts of holistic, relational and inclusive education, defining these values and showing what such educational approaches actually look like in the day-to-day lived reality of early childhood settings and primary schools. This drew on the skills and perspectives of academics and practising educators at early years and primary levels, incorporated children's voices, and sought to conceptualise these ideas both in theory and in practice. Within each country throughout the project, the participants from universities, primary schools and early years settings worked together using creative methodologies that have been highlighted in the literature as fruitful tools for accessing the voices of children and adults within educational settings. These included photography (Kleine et al. 2016), video clips (Palaiologou 2008), children's art work (Kiely et al. 2019), focus groups (Hall, Wall 2019), reflective journals (Mukherji, Albon 2018), and learning stories (Carr, Lee 2012). A 'mosaic approach' (Clark, Moss 2009) was thereby taken to creating a rich and vibrant picture of holistic, relational and inclusive education in practice. The multiplicity of children's voices (O'Toole, Hayes 2019) was particularly highlighted throughout, and a focus on continuously defining values and improving practice was maintained, as is crucial for good action research (Sullivan et al. 2016).

The project was structured around eight key international events, with ongoing incountry work continuing in the intervening periods, whereby universities, primary schools and early years settings collaborated to develop their specific strand of the project and create workshops through which to share their work with international colleagues. Between December 2017 and January 2020, the team held four Transnational Project Management Meetings (TPMM's) and four Learning, Teaching and Training Activities (LTTA's). The first TPMM took place in Dublin, Ireland in December 2017, and was a crucially important opportunity for relationship building. While each of the team members was interconnected with others, this was the first time that the whole team were together, and time and space were allowed for simply getting to know each other, and beginning to establish our initial understanding of the three concepts that would be the focus of our work. While synergies in our perspectives were identified, so also were tensions, with differing, and potentially conflicting, theoretical influences from a range of disciplines including psychology, sociology, anthropology and pedagogy, as well as similarities and differences in practices across countries and across educational levels (early years and primary). As one 
participant reflected, "At the beginning I have to confess I had no idea what you were talking about! But over time it started to make sense". It was important at this point to allow these tensions to emerge and to sit with the 'not knowing'. Steve Potter (2020) refers to the idea of 'hovering and shimmering', whereby we 'hover' above a situation and try to see the whole picture, while also 'shimmering' between potentially opposing viewpoints and perspectives, bringing to life the multiple possibilities of seeing more than one perspective at a time. He maintains that this promotes reflection, mindfulness, mentalising, meaningmaking and testing a point of view. A presentation by Steve Potter to the THRIECE team early in the project on this concept supported us to maintain and sit with the sense of 'not knowing' that can be integral to PAR. The practicalities of working together as a team were also developed at the first TPMM, including budgeting, project communications plan, reporting roles and responsibilities, risk assessment and a clear project plan. The purpose of the three further TPMM's from that point on was to review, update and respond to the practical project management plans made in this initial meeting.

The first LTTA was held in Dublin, Ireland in February 2018, and began with an opportunity for each country team to give an update on the work and partnership that had been ongoing in Ireland, Poland and Portugal since the previous meeting. As a team, we then spent time exploring children's rights as the ethical underpinning for THRIECE. The focus of discussion was "How can we ensure that an understanding of children's rights, cultures, capacities and needs underpin all THRIECE methodologies?", and as a team we developed our application for ethical approval through the ethics committee of the lead institution MIE, which was subsequently granted. We also explored the requirements of online modules from the perspectives of the three countries and the three educational levels, and a highlight of the LTTA was a presentation from one of the THRIECE Associate Partners, Dr Nick Barnes of the Association of Cognitive Analytic Therapy (ACAT) on defining and measuring a relational understanding of resilience. While we were moving towards a more common understanding of our core concepts, it was agreed that the complexity of these issues could not be underestimated but rather should be embraced.

LTTA2 was led by the Portuguese team and was held in Porto, Portugal in May 2018. It focused on the 'Inclusive' strand of the project, and team members from the university, primary school and early years setting developed workshops for the international team sharing the understanding of 'inclusive' education that had been developed in their work together. The workshops involved movement-based and playful activities as well as more cognitive approaches, and there was also an opportunity to visit the educational settings to see their practice in action. Additionally, the intertwined nature of the three core concepts was elaborated, with the Irish and Polish teams showing how their work, while focused on the relational and holistic strands of the project respectively, was also inclusive in nature.

LTTA3 was led by the Polish team and was held in Gdansk and Gdynia, Poland, in November 2018. It foregrounded the 'Holistic' strand of the project, and again team members from the university, primary school and early years setting developed workshops for the international team sharing their understanding of 'holistic' education. Like in Portugal, 
these workshops moved beyond the cognitive domain, and engaged with picture books and drama-based methodologies to explore the concept, and there was an opportunity to see the practice of the Polish primary school and early years settings in reality. The Irish and Portuguese teams had the opportunity to feed into the understanding of the holistic strand by drawing on their own in-country work.

LTTA4 took place in May 2019 and was led by the Irish team to explore the 'Relational' strand of the project. Again the workshops engaged with creative methods to share the work of the Irish university, primary school and early years setting, including an artistic session working with clay to create relational objects for sharing a meal ${ }^{2}$. Visits to the primary and early years settings allowed again for cross-cultural comparison of practices. While the 'relational' element was foregrounded in this LTTA, there were also opportunities for 'cross-pollination' of ideas and materials across the three strands.

The project concluded in January 2020 with the successful completion of the three online modules for early childhood and primary educators and three very well attended international conferences, one in each participant country.

\section{PAR: living our values}

The THRIECE project drew on both interpretivist and critical paradigms, "finding common ground between discourses that were traditionally polarised, triangulating ideas from different aspects and in doing so creating a completely new perspective" (O'Toole et al. 2019: 176). Participant Action Research was the ideal approach for THRIECE as it allowed us to 'own' our positionality. Rather than being limited by the objectivity and neutrality required of traditional positivist researchers, within a PAR approach researchers can, indeed must, explicitly state their values, and much of the work of action research is to elucidate, interrogate and clarify one's values so that they can be more fully lived in practice (McDonagh et al. 2019). Participant Action Research requires researchers to "explore how [they] might engage in an authentic, practical and personalized framework for conducting critical reflection and action on [their] educational practice" (Sullivan et al. 2016: 1).

From the beginning, the core values of 'holistic', 'relational' and 'inclusive' research guided the processes and practice of THRIECE, and reflection on this was built into the project as activities and agenda items within the national and international activities, and through formal evaluation processes. A 'holistic' approach was taken in that team members did not simply engage with the concepts only cognitively. Instead, they used their bodies, their senses, their movement and their creativity through art, drama, games, pictures, etc. to develop a rich and nuanced understanding. While direction and coordination was provided across the project, each country, educational setting and individual person was facilitated to contribute in the way that suited them best; as one participant reflected,

2 The clay workshop was provided by Breadfellows artist Clare Breen (www.breadfellows.school, 10.08.2020). 
We had time constraints, but we also allowed for the complexity, the imagination required.

[We had] big boundaries to do things in our own way; this freedom is unusual.

The wide range of methodological tools used in each country also captured a truly holistic picture of good educational practice.

THRIECE was also 'relational' to its core. The development of the research team was rooted in pre-existing relationships, and the further nurture of interpersonal relationships was explicitly valued and given space as a priority goal:

THRIECE made life richer. It started out personal, became professional, but it quickly became personal again.

We started off trying to remember names and ended up friends.

There was a mindful approach to creating safe, relational spaces that allowed tensions and potentially conflicting ideas to be respectfully explored. This permitted a comfort with 'not knowing', allowing the process to unfold, trusting each other to be able to question theories, and long-held beliefs, practices, and ideas. In reflecting on the process one team member indicated,

The discussions were rich and robust. They enabled us to build trust and curiosity about others' perspectives, thus creating a very rich and fertile learning environment.

An 'inclusive' ethos also underpinned all work, breaking down traditional power boundaries between universities, primary schools, and early years settings. Universities did not do research on educational settings as in traditional research - early educators, primary teachers and university academics co-constructed their understanding of what it means to be holistic, relational and inclusive, conceptually and in practice; one early childhood educator reflected,

I remember feeling so daunted on the first day but I learned so much and from the beginning felt so included.

An inclusive approach was also taken to roles within settings - all staff in the educational settings were included in the project, from teachers to secretaries to special needs assistants to traffic wardens to librarians, etc. In reflecting on the experience, one team member noted,

The project is a very good example of the effective international cooperation between academic staff from different countries and between academic staff and preschool/school staff... [through a] climate and substantive contents of support. 
Cross-cultural sharing and respect for diversity were underpinning values evidenced in visits to culturally important sites in each country to allow for cultural exchange, and the visits to the educational settings were particularly highlighted by participants as facilitating a deep understanding of education within its cultural contexts:

a unique opportunity to observe the education of children in context. The visits to the kindergarten classrooms and primary school classes were so rich and meaningful learning experiences that even today all team members talk about them and refer to their impact on thinking and their own educational practices.

Sharing of meals allowed for further cross-cultural understanding rooted in traditions of food, and specific dietary needs and accessibility requirements were supported for all team members. Thus, the PAR approach facilitated the ability to exemplify project values throughout.

\section{Reflecting on PAR as an approach for early childhood and primary education}

Conducting Participant Action Research is not a matter of taking old, established approaches to research and adapting them. Rather it requires a complete shift in world view (Sullivan et al. 2016). Concepts such as personal values and personal reflection on one's own practice that are considered 'unscientific' and 'biased' in traditional research are not only permissible within PAR, they are of central concern. Whereas traditional research approaches are linear and relatively predictable, with a hypothesis, a data-gathering phase and analysis of outcomes along pre-defined indicators and measures, one of the key features of PAR is its 'messiness' and unpredictability - within PAR, the findings of one phase of a project dictate the next, and methods, ideas and even the questions we ask evolve as our understanding of the complexities of the context and people being studied evolve. This can feel deeply uncomfortable at times during a PAR project; as one participant put it,

Sometimes I found myself thinking, if I knew I never would have...

However, as Karen Goodnough (2008: 431) states, "messiness and uncertainty are inherent and necessary elements of action research and... these elements need to be explicit for the benefit of those who engage in and facilitate PAR". In fact, acknowledging and embracing the non-linear nature of PAR can be liberating for all participants as it allows for respectful, real, responsive (at personal and contextual levels), interdisciplinary approaches, as illustrated by THRIECE:

It was a personal challenge... differences in our work... at the beginning I didn't know what we would achieve but it's a really good feeling because I never thought we could achieve so much. I've been in a lot of projects but nothing like this. 
For this reason, Libby Porter et al. (2015) refer to the 'beautiful messiness' of action research, and Bernie Sullivan et al. (2016) indicate that once this unpredictability is embraced, action research can provide a powerful vehicle for educational transformation. The outcomes of PAR are not likely to be generalisable to all other educational settings, as contextual and personal factors are so deeply embedded in its processes and findings, but nevertheless there may be some transferability for other practitioners and settings, once adapted for context.

Such a worldview highlights how only measuring what is easily measurable is problematic. One of the most important freedoms afforded by PAR is that it allows for expression of and development of evidence for 'gut feelings' of experienced educators. Philosophers of education have long identified the 'tacit' knowledge that educators hold. Elliot Eisner (1985) describes educators as connoiseurs engaged in artful doing. Donald Schön (1983) highlights the importance of 'reflection in action', in which "the practitioner allows himself to experience surprise, puzzlement, or confusion in a situation which he finds uncertain or unique. He reflects on the phenomenon before him, and on the prior understandings which have been implicit in his behavior"3 (Schön 1983: 68). This 'tacit' knowledge is often intuitive and difficult to explain; educators may be confronted with "situations of uncertainty, instability, uniqueness, and value conflict" (Schön 1983: 49-51) and must often act spontaneously. Thus, educational practice may be developed not through rational thought processes, but rather when educators 'have a feel' for the right course of action. Max van Manen (1990) also highlights such lived experiences rather than cognitive, objective interpretations and refers to 'pathic' knowledge rooted in the body - "the lived, felt, experienced mode often overlooked because of our experience with it" (Ó Breacháin 2016: 52).

One of the central benefits of PAR is that it allows space for the tacit knowledge of expert educators to be explored, and can provide language for them to express and defend what they know to be right in their practice. This was a core aim of THRIECE - to empower educators to withstand systemic pressures to ignore process-based elements like relationships and interactions in favour of structural and outcomes measures, and allow them space and voice to foreground holistic, relational and inclusive approaches in their work. This was one of the key successes of the project that perhaps would not have been achievable outside of a PAR approach, and it was hugely valued by participants:

It inspired me to find new solutions... I have always wanted to create new ways, thank you. It supported our gut instinct that what we knew was right, was actually right.

It was my first international project, it gave me support for the unknown and the language for what we do - we are relational, holistic and inclusive.

Another key finding of the THRIECE project has been confirmation of our sense of the crucial nature of relationships. Extensive theoretical (Bowlby 1969; Ryle, Kerr 2002;

3 As was common at the time, Schön uses gendered language here, but these ideas may be applied equally to male and female educators. 
Bronfenbrenner, Morris 2006; Trevarthen 2017) and research-based (Hamre, Pianta 2006; Riley 2011; O’Connor 2013; Kiely et al. 2019) evidence has established the uncomfortably unmeasurable fact that the success of many education-based strategies may have little to do with the strategies themselves, and more to do with the relationships underpinning them. THRIECE sometimes involved challenge to deeply held beliefs and long-cherished approaches to work; when people feel under threat the ability to explore such dangerous territory may shut down as we enter 'fight-flight-freeze' mode (Rogers 1995), so the success of THRIECE specifically and PAR generally is significantly and crucially dependent on safe psychological and relational spaces in which it is okay to wonder, muse and even be wrong. This can lead to deep and personal learning:

The project was very important to me. I learned a lot about myself, other people, other cultures.

The value of visits to the educational settings for transnational and cross-level understanding cannot be over-estimated in this context, and these also needed to be conducted within a relational, trusting space, as it is potentially very exposing for educators to demonstrate their settings and their practice to an international audience:

Visiting your centres meant so much but having you visit ours meant so much too - telling staff that people thought their work was good meant the world.

\section{Conclusion}

This paper explores the potential benefits of Participant Action Research for early childhood and primary education using the illustrative example of the THRIECE project. Since the work of THRIECE specifically and PAR generally is so rooted in its cultural, personal and relational contexts, it is difficult to draw any generalisable conclusions from it. However, there are some potentially transferable ideas that may be useful to other academic and practitioner researchers. Firstly, the central finding is that PAR may provide unique opportunities to develop respectful, relevant, inclusive and useful research for early childhood and primary education, in spite of the challenges inherent in its non-linear nature. Secondly, those who use PAR must embrace the messiness, expect to feel confused and unsure at times, and allow time to sit with not knowing, 'hovering' above the situation and 'shimmering' between potentially opposing viewpoints. Lastly, and perhaps most importantly, PAR is deeply relational (as are all things educational and indeed perhaps all things in life). Relationship building between participants is a vital element of the work of PAR and should not just be left to chance. Rather, values of respectful support should be explicitly articulated from the beginning and throughout a project, and time and space should be allocated for participants to create safe, relational spaces in which to work and develop their thinking and practices. 
In short, we argue that approaches to research and education should be holistic, relational and inclusive, and that Participant Action Research can provide a powerfully transformative vehicle for such approaches.

\section{References}

Baumfield V., Hall E., Wall K. (2013), Action Research in Education: Learning Through Practitioner Enquiry. London, Sage Publications.

Blair E. (2010), How does telling the truth help educational action research? "Educational Action Research", 18(3).

Bowlby J. (1969), Attachment and Loss. Vol. 1: Attachment. New York, Basic Books.

Bronfenbrenner U., Morris P.A. (2006), The Bioecological Model of Human Development. In: R.M. Lerner, W.E. Damon (eds.), Handbook of Child Psychology. Vol. 1: Theoretical Models of Human Development. West Sussex, John Wiley and Sons.

Carr M., Lee W. (2012), Learning stories: Constructing learner identities in early education. London, Sage.

Clark A., Moss P. (2009), Listening to Young Children: The Mosaic Approach. London, National Children's Bureau and Joseph Rowntree Foundation.

Eisner E.W. (1985), The art of educational evaluation: A personal view. Abingdon, Taylor \& Francis.

Gergen K.J. (1973), Social Psychology as History. "Journal of Personality and Social Psychology", 26(2).

Giangreco M.F., Taylor S.J. (2003), Scientifically Based Research and Qualitative Inquiry. "Research and Practice for Persons with Severe Disabilities", 28(3).

Goodnough K. (2008), Dealing with Messiness and Uncertainty in Practitioner Research: The Nature of Participatory Action Research. "Canadian Journal of Education/ Revue Canadienne de l'Éducation", 31(2).

Greenback P. (2003), The Role of Values in Educational Research: The Case for Reflexivity. "British Educational Research Journal", 29(6).

Hall E., Wall K. (2019), Research methods for understanding professional learning. London, Bloomsbury.

Hamre B.K., Pianta R.C. (2006), Student-Teacher Relationships. In: G.G. Bear, K.M. Minke (eds.), Children's needs III: Development, prevention, and intervention. National Association of School Psychologists.

Kiely J., O'Toole L., Brosnan M.H., O’Brien E.Z., O'Keeffe C., Dunne C.M. (2019), Parental Involvement, Engagement and Partnership in their Children's Learning during the Primary School Years. Part 2: (A) Case Studies and (B) Oral Language Workshops. Dublin: NCCA/NPC. https://www.mie.ie/en/research/parental_involvement_engagement_and_partnership_in_their_children\%E2\%80\%99s_education_during_the_primary_school_years/, 10.03.2020.

Kleine D., Pearsons G., Poveda S. (2016), Participatory Methods: Engaging Children's Voices and Experiences in Research. London, Global Kids Online.

Klocker N. (2015), Participatory Action Research: The Distress of (not) Making a Difference. "Emotion, Space and Society", 17. 
Lather P. (2006), Paradigm proliferation as a good thing to think with: Teaching research in education as a wild profusion. "International Journal of Qualitative Studies in Education", 19(1).

McDonagh C., Roche M., Sullivan B., Glenn M. (2019), Enhancing Practice through Classroom Research: A Teacher's Guide to Professional Development. London, Routledge.

McIntyre A. (2008), Participatory Action Research. Thousand Oaks, Sage.

Mukherji P., Albon D. (2018), Research Methods in Early Childhood: An Introductory Guide. London, Sage.

Ó Breacháin A. (2016), Mind-bodies, Interdependent Opposites and Knots: A Phenomenological Inquiry into the Child-Teacher Relationship in Upper Primary School. Doctoral dissertation, $\mathrm{PhD}$ dissertation, University of Exeter.

O'Connor A. (2013), Understanding Transitions in the Early Years: Supporting Change through Attachment and Resilience. Oxon, Routledge.

O'Toole L. (2016), A bio-ecological perspective on educational transition: experiences of children, parents and teachers. Unpublished doctoral thesis. Dublin, Institute of Technology.

O'Toole L., Hayes N. (2019), Supporting positive behaviour in early years settings and primary schools: Relationships, reciprocity and reflective practice. London, Routledge.

O'Toole L., Regan C., Nowak-Łojewska A. (2019), 'To learn with' as an alternative voice for children's education. Introduction to a European project: Teaching for Holistic, Relational and Inclusive Early Childhood Education (THRIECE). "Kwartalnik Pedagogiczny”, 251(1).

Palaiologou I. (2008), Childhood Observation. Cornwall, Learning Matters.

Porter L., Slade C., Butt A., Rosier J., Perkins T., Crookes L., Inch A., Slade J., Bassa F., Petzer B., Winkler T., Saija L., Barry J. (2015), Partnerships of learning for planning education Who is learning what from whom? The beautiful messiness of learning partnerships/ Experiential learning partnerships in Australian and New Zealand higher education planning programmes/ Res non verba? Rediscovering the social purpose of planning (and the university): The Westfield Action Research Project/At the coalface. Take 2: Lessons from students'critical reflections/Education for "cubed change"/ Unsettling planning education through community-engaged teaching and learning: Reflections on the Indigenous Planning Studio. "Planning Theory \& Practice", 16(3).

Potter S. (2020), Therapy with a Map: A Cognitive Analytic Approach to Helping Relationships. Brighton, Pavillion.

Riley P. (2011), Attachment Theory and the Teacher-Student Relationship. London, Routledge.

Rogers C.R. (1995), Client-Centered Therapy: Its Current Practice, Implications and Theory. London, Constable.

Rogoff B. (2003), The Cultural Nature of Human Development. New York, Oxford University Press. Ryle A., Kerr I.B. (2002), Introducing cognitive analytic therapy: Principles and practice. Chichester, John Wiley \& Sons.

Sahlberg P. (2014), Finnish Lessons 2.0: What Can the World Learn from Educational Change in Finland? New York, Teachers College Press.

Schön D. (1983), The Reflective Practitioner: How Professionals Think in Action. Surrey, Ashgate.

Shamrova D.P., Cummings C.E. (2017), Participatory action research (PAR) with children and youth: An integrative review of methodology and PAR outcomes for participants, organizations, and communities. "Children and Youth Services Review", 81.

Spooner F., Browder D.M. (2003), Scientifically Based Research in Education and Students with Low Incidence Disabilities. "Research and Practice for Persons with Severe Disabilities", 28(3). 
Steinberg L., Darling N.E., Fletcher A.C. (1995), Authoritative Parenting and Adolescent Adjustment: An Ecological Journey. In: P. Moen, G.H. Elder Jr., K. Luscher (eds.), Examining Lives in Context: Perspectives on the Ecology of Human Development. Washington, DC, American Psychological Association.

Sullivan B., Glenn M., Roche M., McDonagh C. (2016), Introduction to Critical Reflection and Action for Teacher Researchers. London, Routledge.

Trevarthen C. (2017), The affectionate, intersubjective intelligence of the infant and its innate motives for relational mental health. "International Journal of Cognitive Analytic Therapy and Relational Mental Health", 1.

Urban M., Vandenbroeck M., Van Laere K., Lazzari A., Peeters J. (2012), Towards Competent Systems in Early Childhood Education and Care. Implications for Policy and Practice. "European Journal of Education", 47(4).

van Manen M. (1990), Researching Lived Experience: Human Science for an Action Sensitive Pedagogy. Albany, NY, State University of New York Press.

Zhu Y. (2019), Can Participatory Action Research "Empower" Participants in Adult Educational Studies? "Canadian Journal for the Study of Adult Education", 31(1). 